\title{
The relationship between math personality, math anxiety, test preparation strategy and medication dose calculations in first year nursing students
}

\author{
Kelechi Osahor, Kirsten Woodend, Jane Mackie* \\ Trent/Fleming School of Nursing, Trent University, Canada
}

Received: November 15, 2018

DOI: $10.5430 /$ jnep.v9n8p80

\author{
Accepted: April 8, 2019 \\ Online Published: April 29, 2019 \\ URL: https://doi.org/10.5430/jnep.v9n8p80
}

\begin{abstract}
The objectives of this study were twofold: (1) To determine the predictors of performance on a medication dose calculation test in first year baccalaureate nursing students. The variables studied were: level of math anxiety; math personality; arithmetic ability; program of study; age; and the number of strategies used to prepare for a medication dose calculation test. (2) To determine the factors that affect math anxiety. The variables studied were: arithmetic ability, program of study, math personality, the number of test preparation strategies used and age. Participants consisted of a convenience sample $(n=163)$ from the first year of a Canadian baccalaureate nursing program. Participants completed a mathematics test, which served as a baseline measure of arithmetic ability. They also completed a series of online questionnaires on math anxiety and math personality, age and program of study (compressed program vs. collaborative program). Participants then completed a medication dose calculation test after which they were asked how many different strategies that they had used in preparation for the test. Performance on the medication dose calculation test was regressed on arithmetic ability, mathematics anxiety, program of study, mathematics personality, the number of test preparation strategies and age. Math anxiety was regressed on pretest score, program of study, math personality, the number of test preparation strategies used and age. The variables found to predict performance on the medication dose calculation test were anxiety and program of study. Of the predictors investigated, only the "Inchworm" math personality and number of test preparation strategies used by students significantly predicted anxiety. Strategies to improve nursing students' ability to perform dosage calculations should incorporate anxiety-reducing tactics as anxiety was found to be a key predictor of performance on the medication dose calculation test. These strategies should focus on supporting students who possess an "inchworm" math personality.
\end{abstract}

Key Words: Nursing students, Nursing education, Dose calculations, Medication calculations, Math anxiety, Math personality

\section{INTRODUCTION}

Nurses dedicate approximately $40 \%$ of their time to administering medications; ${ }^{[1]}$ the expansion of nursing roles in medication management demands competency for nurses in this key area to maintain patient safety. ${ }^{[2]}$ It is clear that effective nursing education around accurate performance of medication dose calculations is essential to reduce medication errors. ${ }^{[3]}$ More than half of nursing students around the world fail numeracy and dose calculation tests; ${ }^{[4-8]}$ only $35 \%$ of students can achieve greater than $70 \%$ on a medication dose calculation test. ${ }^{[5]}$ Factors that have an impact on the ability to correctly calculate medication doses have

*Correspondence: Jane Mackie; Email: jmackie@trentu.ca; Address: Trent/Fleming School of Nursing, Trent University, Canada. 
been identified as lack of proficiency in numeracy, challenges in correctly conceptualizing the problem, math anxiety and lack of self-efficacy, teaching strategies, and lack of practice opportunities during education to solidify this skill. ${ }^{[9-16]}$

The aim of this study was to explore which factors are the key predictors of performance on a medication dosage calculation test. The variables studied were: level of math anxiety; program of study; the number of study strategies used to prepare for the test; arithmetic ability; age; and math personality. This study was done with first year nursing students at a Canadian university. While only limited work assessing capacity has been published, ${ }^{[9,12,17]}$ anecdotal evidence from both faculty and students indicate that a problem in accurately calculating medication doses exists in most Canadian schools of nursing.

\subsection{Background}

Nurses dedicate significant time to administering medications to patients; ${ }^{[1]}$ in this role, they are the last defense in a series of systematic checks and balances to prevent medication errors. Medication errors include selection of the wrong medication, missed doses, and improper dose calculations. Inaccurate calculation of doses represents up to one-third of the errors that occur during medication administration. ${ }^{[1,18-21]}$ Errors in calculation when administering medication often result in significant harm to patients. ${ }^{[21-24]}$ Despite the importance of this skill, there is evidence that nursing students often lack a solid foundation in the ability to accurately calculate medication doses. ${ }^{[4-7,15,25,26]}$ Effective education to ensure accurate medication dose calculations can play a key role in reducing medication errors. ${ }^{[3,16]}$

Developing an effective teaching strategy involves an understanding of the barriers to student success in performing medication dose calculations. The key barriers are limited arithmetic procedural fluency, reduced conceptual competence, math anxiety, and lack of self-efficacy around medication calculations. ${ }^{[10,11,13-16,27]}$ The limited opportunity to practice skills during education also reduces proficiency in medication dose calculations. ${ }^{[9,28,29]}$ Other factors that may alter the ability to accurately calculate medication doses include math personality, ${ }^{[30]}$ study strategies utilized to prepare for a dosage calculation test ${ }^{[28]}$ and prior university experience. ${ }^{[31]}$

In analyzing student errors it appears that both conceptual errors (inability to understand the question) and procedural errors (arithmetic errors) are made by nursing students when performing medication dose calculations. ${ }^{[12,15,26,32,33]}$ Procedural errors result from difficulty in performing basic arithmetic tasks such as division and multiplication; these skills are learned in elementary school. ${ }^{[34]}$ Many nursing schools prohibit students from using calculators on dosage calculation tests, ${ }^{[26,32,34]}$ arguing that nurses should not depend on calculators to ensure the accuracy of their dosage calculations. The simple arithmetic errors that arise from solving math problems without using a calculator are a significant cause of errors on drug calculation tests. ${ }^{[35]}$ It is clear that "... much of the mathematics needed for practice is actually based on Grades 5-9 mathematics content, yet requires the lucid application of these skills to more complex formulas, and often under stressful conditions". ${ }^{\left[{ }^{[6]} \text { This aptly }\right.}$ illustrates the issues: nursing students do not remember the basic arithmetic skills required, such as multiplication tables, and feel lost without the security of a calculator, leading to the cycle of math anxiety, reduced self-efficacy, and lack of success. ${ }^{[10]}$

Math anxiety refers to feelings of apprehension and tension experienced by a person that interfere with performance on math-related tasks. ${ }^{[37]}$ Significant math anxiety exists in the student nurse population. ${ }^{[10,16,37]}$ Students with math anxiety struggle to perform adequately when tested due to feelings of anxiety about their ability to perform the task correctly. ${ }^{[10,13,37]}$ Nursing students with low self-efficacy and higher math anxiety have consistently been reported to experience reduced performance on medication dose calculation tests. ${ }^{[7,10,16,38]}$ Nursing students who report anxiety believe it to be related to an understanding of the real world consequences of performing incorrect dosage calculations in a clinical setting; $[25,28,36]$ "as future nurses, students are acutely aware of their responsibility and accountability in drug calculation and the importance of checking answers and getting the calculations right". ${ }^{[8]}$ In a test situation, the more significant the consequence of failure, the greater the level of math anxiety. ${ }^{[39]}$

Math personality refers to the way in which an individual solves a math problem, and is based on the assessment of Cognitive Style in Mathematics. ${ }^{[40]}$ The "Inchworm" and the "Grasshopper" personalities are at the opposite end of the spectrum in math personality. ${ }^{[40]}$ An Inchworm is an individual who solves math problems using a series of sequential steps that must each be correct in order to arrive at the right answer; this individual often uses paper and pen and the order of steps is very mechanical and precise. A Grasshopper on the other hand takes a 'big picture' view of the problem, analyzing the relationship between numbers in order to arrive at the right answer; this individual typically performs mental math without pen and paper. ${ }^{[40]}$ Information about math personality and performance on a medication dose calculation test by nursing students is very limited. The original assessment of math personality found a predominance of Inch- 
worm math personality ( $83 \%$ ), and a very limited presence of the Grasshopper math personality (3\%); the remainder (14\%) were classified as Intermediate in their math personality. ${ }^{[30]}$ Math personality explained $17 \%$ of the variance in the ability to calculate medication doses. ${ }^{[30]}$ A more recent analysis of math personality found that Grasshoppers make the fewest errors and Inchworms make the greatest number of errors when performing medication dose calculations. ${ }^{[15]}$ This study found a similar distribution of $66 \%$ Intermediate, $25 \%$ Inchworm, and 9\% Grasshopper math personalities in nursing students. ${ }^{[15]}$

To the best of our knowledge, no information exists concerning the potential impact of age or program on the ability of nursing students to perform on a medication dose calculation test. At our School of Nursing, students may be enrolled in one of two programs. Students entering the collaborative program have little to no previous university experience, while students admitted to the compressed program students have significant previous university experience and move through the program more quickly. While there is evidence to suggest that compressed students have specific coping strategies to deal with the speed and pressure of their program, ${ }^{[31]}$ no work has been found specifically in relation to their success on medication dose calculation tests. An understanding of these individual factors may help educators to be more successful in designing effective strategies in education around medication dose calculations that target specific populations

To the best of our knowledge, no information exists concerning the potential impact of the type of preparation for a test on the ability of nursing students to perform on a medication dose calculation test. This includes the number of different strategies that are used by a student in preparation for a test. This factor is important because students have access to a variety of different practices strategies, some of which may be more useful than others.

This study is designed to determine which of these six factors have an impact on the ability of nursing students to succeed on a medication dose calculation test. These findings will be used to inform nursing education around effective strategies to help nursing students develop the ability to accurately calculate medication doses.

\subsection{Research questions}

1) Do arithmetic ability, mathematics anxiety, program of study, mathematics personality, the number of test preparation strategies, and/or age predict performance on a medication dose calculation test? 2) Do baseline test score, program of study, math personality, the number of test strategies, and/or age predict math anxiety?

\section{METHODS}

This study was conducted with a convenience sample $(\mathrm{n}=$ 163) of first year baccalaureate nursing students at a university in Canada using a cross-sectional design. The rationale for choosing a cross sectional design was to enable the researchers compare each proposed variable across a single convenience sample population in a single time period; in order to determine which variable best predicted performance on medication dosage calculations. Ethics approval for this study was obtained from the University Research Ethics Board. Participating students were recruited from the first year class in which medication dose calculations are taught. Students were informed of the study by an in class presentation at the beginning of the semester. Interested students then filled out a web-form that contained consent forms, and the other surveys utilised in the studyThere were three phases to the study. In Phase 1, participants completed a quiz to assess their ability to solve basic arithmetic problems involving addition, subtraction, multiplication, division, and manipulation of decimals and fractions. In Phase 2, participants completed a comprehensive online survey in which information on math anxiety, math personality, the number of strategies used to prepare for the medication dose calculation test, and program of study was collected. In Phase 3 , participants completed a medication dosage calculation test on paper without a calculator. The avoidance of calculators was based on a philosophical decision made by the math committee of the school. This test was completed six weeks after students learned how to perform medication dose calculations. Data were collected over a four month period (September to December) in 2015.

\subsection{Math anxiety}

Math Anxiety was evaluated using the Abbreviated Math Anxiety Rating Scale (A-MARS) created by Alexander and Martray. ${ }^{[41]}$ The A-MARS is a compilation of 25 questions that qualitatively measure the amount of anxiety a participant feels about specific aspects of mathematics, on a scale of 'not at all' to 'very much'. For the purpose of this study, quantitative values were attached to the four potential responses for each question in the A-MARS as follows: 'Not at all', indicating no math anxiety, was assigned a value of 0 ; ' a little math anxiety' was assigned the value of 1; 'a fair amount of math anxiety' was assigned a value of 2; 'much math anxiety' was assigned a value of 3; and 'very much math anxiety' was assigned a value of 4 . An average score for all questions was calculated to determine math anxiety for each participant. Anxiety scores can range from 0 to 4 . The 25 item version of this tool has been validated and is both internally consistent and reliable. ${ }^{[41]}$ 


\subsection{Math personality}

In order to determine math personality survey, six questions were selected, with permission, from a more extensive survey developed by Dr. S. Chinn. ${ }^{[42]}$ Students were sorted into two groups (Inchworms and Grasshoppers) based on their answers to six questions about how they would approach arithmetic questions. Participants were not required to answer the arithmetic questions, they simply had to think about their process as if they were answering the questions. To provide quantitative data, responses associated with a Grasshopper personality were assigned a value of 1, while Inchworm personality responses were assigned a value of 0.5. Participants scoring a total value of 3-4 were coded as an Inchworm personality while participants scoring 5-6 were coded as a Grasshopper personality; students who scored 4-5 were classified as an Intermediate math personality. The math personality survey was used by Chinn in 1783 children and 792 adults aged 16 years to 59 years old. ${ }^{[2]}$ The psychometric properties of this tool have not been reported.

\subsection{Arithmetic ability}

Arithmetic ability, or the knowledge of basic mathematical skills involved in division, multiplication, ratios, fractions and decimals was evaluated using a review test from the textbook used to teach medication dose calculations. Students were asked to refrain from using a calculator while completing this test; submission of a hardcopy of the test showing manual calculations was required. Percentage scores were then compiled for participants and used as a baseline estimate for arithmetic ability.

\subsection{Program of study}

Participants identified whether they were registered in the collaborative or compressed nursing program. The collaborative program is a first-degree program with students mainly from high school or college while the compressed program is an accelerated program for students with at least two years of university experience.

\subsection{Test-preparation strategies}

Students were asked to check which options they used to prepare for the medication dose calculation test from a series of four different options (textbook, math review videos, individual tutoring sessions, none). In order to analyze the relationship between score on the medication dose calculation test and the number of interventions utilized, students were split into two groups. Those who used between $0-2$ interventions were grouped together, and those who used 3-4 interventions were grouped together.

Published by Sciedu Press

\subsection{Analysis}

Frequencies, means, and standard deviations were calculated to describe the respondent profile. Chi-square tests and t-tests were used to compare the profiles of students in the compressed and collaborative programs. Multiple linear analysis was used to answer the two main research questions. The level of significance (type I error rate) is 0.05 .

The first research question, "Do arithmetic ability, mathematics anxiety, program of study, mathematics personality, the number of test preparation strategies, and/or age predict medication dose calculation test results?" was tested using multiple linear regression. The variables selected for inclusion in the linear regression which were outlined in the research question with the exception of 'mathematics personality' and age. Univariate correlations between each of the independent variables and drug calculation test results were done. The Spearman rho for math personality and mid score was rho $=-.003(p=.975)$; for this reason, math personality was not included in the regression analysis. As age data was collected as a categorical variable and the numbers of students in age groups higher than 20 were relatively small, age was dichotomized (20 years or fewer, greater than 20 years of age). The Cramer's V for age dichotomized and program was 0.84 . Only one of the two variables, program of study, was included in the regression analysis because the strong correlation between these two variables suggested they were essentially measuring the same thing.

While math anxiety scores were normally distributed, neither the baseline test scores (arithmetic ability) or the mid-term drug calculation test scores were normally distributed. Both variables were transformed $(\log 10(\mathrm{~K}-\mathrm{X})$ transformation for arithmetic ability and SQRT(K-X) for mid-term drug calculation test scores). Continuous variables initially included in the analysis were arithmetic ability, mathematics anxiety, and the number of test preparation strategies; program of study, both mathematics personalities (inchworm vs not and grasshopper vs not)y and age were both dichotomous variables so dummy coding was not required. The remaining assumptions for linear regression were tested. There is no first order linear auto-correlation; relationships between each independent variable and the dependent variable are linear, there is homogeneity of variance (homoscedasticity) and no multicollinearity. A minimum of five subjects per variable and optimally 20 subjects per variable have been recommended for multiple linear regression; ${ }^{[43]}$ there are 7 independent variables in this analysis and 163 students participated such that there are 23 subjects per variable.

The second research question, "Do baseline test score, program of study, math personality, the number of test strategies, 
and/or age predict math anxiety?" was also testing using multiple linear regression analysis. The variables selected for inclusion in the linear regression were outlined in the research question. As in the previous analysis baseline test score, and the number of test strategies used were treated as continuous variables; program of study, mathematics personality and age were categorical/dichotomous variables. All assumptions for doing a linear regression analysis were met. There are 6 independent variables in this analysis and 163 students participated such that there are 27 subjects per variable.

Based on the results of the previous analysis, two regression models were calculated to determine the path coefficients and "e-values" (error variances) for the model shown in Figure 1. The program of study and math anxiety were regressed on medication dose calculation test results; and math personality (Inchworm) and number of test preparation strategies were regressed on math anxiety.

\section{RESUlts}

A total of 163 students participated in the study, 55 from the compressed program and 108 from the collaborative program. The distribution of ages between students in the collaborative and compressed programs differed significantly $\left(\chi^{2}=\right.$ $116.32, \mathrm{p}<0.001$ ) with most students in the collaborative program $(92 \%)$ being under the age of 20 and most students in the compressed program $(73 \%)$ being between the ages of 21 and 25 . Students in the collaborative program were more anxious (t161 $=-2.67, p=.008)$ and used more test preparation strategies $(\mathrm{t} 161=-2.77, p=.006)$ than students in the compressed program. There was no significant difference in the arithmetic baseline test score or in the distribution of math personalities between the two groups (see Table 1).

Table 1. Respondent profile

\begin{tabular}{lll}
\hline & $\begin{array}{l}\text { Compressed } \\
\text { Program }\end{array}$ & $\begin{array}{l}\text { Collaborative } \\
\text { Program }\end{array}$ \\
\hline $\begin{array}{l}\text { Age (\#/\%) } \\
16-20 \text { yrs }\end{array}$ & $3(5.45)$ & $99(91.67)$ \\
$21-25$ yrs & $40(72.73)$ & $8(7.41)$ \\
$26-30$ yrs & $6(10.91)$ & $1(0.93)$ \\
$30-34$ yrs & $6(10.91)$ & $0(0)$ \\
Math Personality (\#/\%) & & \\
Inchworm & $36(65.45)$ & $66(61.11)$ \\
Intermediate & $11(20.00)$ & $24(22.22)$ \\
Grasshopper & $8(14.55)$ & $17(15.74)$ \\
Anxiety & $1.29 \pm .73$ & $1.61 \pm .73$ \\
Baseline test score & $87 \% \pm 18$ & $92 \% \pm 14$ \\
Number of test-preparation strategies & $1.6 \pm .68$ & $1.9 \pm .78$ \\
Dose calculation test score (\%) & $91.31 \pm 8.42$ & $86.80 \pm 9.74$ \\
\hline
\end{tabular}

\subsection{Research question 1}

A multiple regression was conducted predicting mid-term drug calculation test results. Overall, the regression was significant, $F(4,158)=6.54, p<.0005 . R 2=.142$. Of the predictors investigated, only anxiety and program of study significantly predicted score on the medication dose calculation test (Table 2).

Table 2. Predictors of medication dose calculation test results

\begin{tabular}{lllll}
\hline & b & SE b & 及 & p \\
\hline Constant & 1.481 & .438 & & \\
Baseline test score & .057 & .185 & .023 & .757 \\
Math anxiety & .386 & .147 & .218 & .01 \\
Program of study & .488 & .214 & .175 & .024 \\
Number of preparation strategies used & .217 & .143 & .126 & .132 \\
\hline
\end{tabular}

Notes. $R^{2}=.142 ; R_{\text {adj }}^{2}=.140$.

Table 3. Predictors of math anxiety

\begin{tabular}{lllll}
\hline & $\mathbf{b}$ & SE $\mathbf{b}$ & $\boldsymbol{\beta}$ & \multicolumn{1}{c}{$\boldsymbol{p}$} \\
\hline Constant & .149 & .262 & .303 \\
Pre-test score & .103 & .099 & .073 \\
Program of study & .214 & .114 & .136 & .061 \\
Mathematics personality & & & .192 \\
Inchworm & .296 & .130 & .012 & .886 \\
Grasshopper & .025 & .175 & .415 & $p<.0005$ \\
Number of preparation strategies used & .405 & .070 & & \\
\hline
\end{tabular}

Notes. $R^{2}=.245 ; R_{\text {adj }}^{2}=.220$. 


\subsection{Research question 2}

As outline above, age was omitted from the regression analysis. Math personality was retained because in univariate analysis there was some relationship to anxiety. Dummy variable coding was done for the variable mathematics personality (Inchworm versus other, Grasshopper versus other). A multiple regression was conducted predicting math anxiety. Overall, the regression was significant, $\mathrm{F}(5,156)=10.106$ ,$p<.0005 . R^{2}=.245$. Of the predictors investigated, only math personality (Inchworm) and number of test preparation strategies used by the students significantly predicted scores on the medication dose calculation test (see Table 3).

\subsection{Relationship between variables}

Path coefficients ( $\beta$ 's) and unexplained variance terms (e) are shown in Figure 1. Both the numbers of test preparation strategies used and math personality (Inchworm) predict student's math anxiety, with the numbers of test preparation strategies having the stronger impact. Neither has any direct impact on medication dose calculation scores. Math anxiety and the student's program of study are directly related to medication dose calculation scores with the strength of the relationship between anxiety and medication dose calculation test scores being in the moderate range.

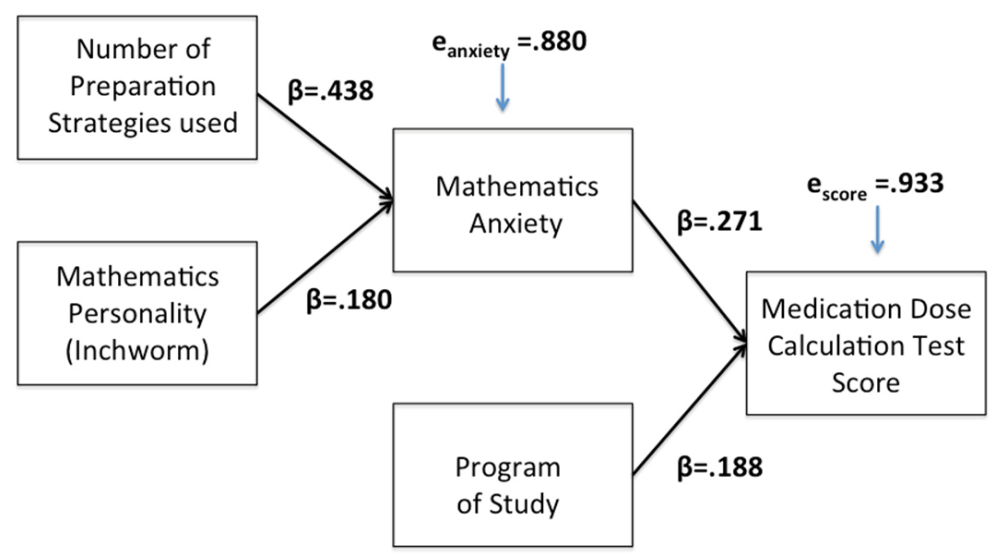

Figure 1. Relationship between variables

\section{Discussion}

Nurses spend a significant amount of time administering medications and yet medication errors continue; a significant proportion of these errors involve calculation errors in medications such as anti-infective or cardiac drugs, for which errors produce potential significant harm. ${ }^{[18,19,21]}$ Successful nursing student education that results in accurate calculation of medication doses is important to reduce medication errors in practice. Understanding the key factors that lead to reduced ability to accurately perform mediation dose calculations can provide opportunities to devise educational program factors that will improve accuracy of medication dose calculations in nursing students in order to improve medication safety in patients.

The results from this study suggest that Canadian first year baccalaureate nursing students are similar but not identical to nursing students around the world when considering the parameters that reduce performance on medication dose calculation tests. Math anxiety and program of study were found to impact the ability to perform medication dose calculations, while math personality, arithmetic ability, and the number of strategies used to prepare for the test did not. Awareness of

Published by Sciedu Press which factors are linked to the ability to accurately calculate medication doses can be used to design teaching strategies to improve the ability of nursing students to calculate medication doses accurately.

Math anxiety has been documented to negatively impact the calculation of medication doses in nursing students and practicing nurses across the world. ${ }^{[6,10,13,16,37,44]}$ This study is the first to measure math anxiety levels in Canadian nursing students, though the presence of math anxiety in Canadian nursing students and practicing nurses has been noted. ${ }^{[36]}$ While the average math anxiety level reported in the study was only mild ( 1.5 out of a possible 4 ), math anxiety significantly reduced performance on the medication dose calculation test (see Table 2) in our students. It is not surprising that math anxiety is a key factor because students feel the burden of correctly calculating doses to prevent harm. ${ }^{[8,25,36]}$ Math anxiety may also be associated with the paper-and-pencil test situation, which is not similar to the clinical situation, ${ }^{[28]}$ or if passing the test is linked to a significant outcome such as graduation ${ }^{[39]}$ or progression to the next clinical course. Lower self-efficacy is also associated with increased anxiety and reduced ability to accurately perform medication dose 
calculations. $^{[10,13,38]}$ Since math anxiety was found to be a strong predictor of performance of first year baccalaureate nursing students on a medication dose calculation test (see Table 2), strategies to reduce math anxiety levels in nursing students could improve performance of first year nursing students on a medication dose calculation test.

One potential intervention is the use of a calculator; students were not allowed to use a calculator during the testing which has been shown to decrease performance and increase math anxiety; ${ }^{[34]}$ this is linked to decreased self-efficacy in math. ${ }^{[10]}$ Typically, schools of nursing do not allow calculator use during testing. ${ }^{[4,12,32,34,45]}$ Use of a calculator during testing has been found to lead to improved accuracy in medication dose calculations when a direct comparison was made; ${ }^{[35]}$ this may be linked to increased self-efficacy. ${ }^{[10]}$ When considering Reason's Swiss cheese model and systems approach to reduce errors, ${ }^{[46]}$ the reluctance to use a calculator during testing may be a latent error by nursing educators that should be corrected. Alternatively, incorrect data input produces incorrect answers would be classified according to Reason as an active error by the student. ${ }^{[46]}$ A basic arithmetic baseline test without a calculator has been suggested as way to determine arithmetic ability before teaching begins. ${ }^{[33]}$ There is limited information about whether to use a calculator during the actual teaching of medication dose calculations. The effective use of calculators in teaching and testing is therefore a key future question for investigation.

The program of study in which a student is enrolled was also found to be predictive of performance of first year baccalaureate students on a medication dose calculation test (see Table 2). Participants in this study were enrolled in one of two programs at the school, either the collaborative or the compressed program. The collaborative program consists of students who entered directly from high school or after a year within a college program. The compressed, or accelerated program consists of students who have had university experience; many students have completed a previous degree. Both programs require identical high school entry courses, including one math credit, and the entrance grade averages are similar. The university-level entry requirements for the compressed students do not include mathematics, and the students come from a wide variety of university degree programs. Compressed students achieved mastery of medication calculations, defined as a result of at least $90 \%$ on the medication dose calculation test, at a rate much higher than collaborative students $(45 \%$ collaborative students vs. $69 \%$ compressed students, $\left.\chi^{2}=8.24, p=.004\right)$. Upon closer examination, the connection between this parameter and performance is believed to be linked to math anxiety. Math anxiety in compressed students was significantly lower than anxiety in collaborative students (see Table 1). Compressed students have had the opportunity to develop strategies to manage their anxiety during their previous university careers, ${ }^{[31]}$ whereas collaborative students are adjusting to the first year of university as well as learning to calculate medication doses. Program and age are strongly correlated with students in the compressed program being significantly older. These older students may have had more time and opportunity to learn to manage their math anxiety (see Table 1) because they do develop specific coping strategies to deal with the speed and pressure of their program. ${ }^{[31]}$ To our knowledge, this is the first time the difference between compressed and collaborative students has been explored with respect to ability to calculate medication doses. An acknowledgement of the differences between these groups of students will allow the development of educational resources best suited to support each of these different nursing student populations.

It was surprising to find no significant relationship between arithmetic ability (baseline test scores) and scores on the medication dose calculation test (see Table 2), because many studies have found that arithmetic errors are a common source of error when nursing students are calculating medication doses. ${ }^{[4,5,26,32]}$ The lack of prediction found in the current study could be due to several reasons. First, as a take-home test, the review test was the least controlled variable in this study. There was no way to confirm that students had abstained from using calculators or working on this assignment in groups. Secondly, there was an opportunity to review basic arithmetic skills during the learning of medication dose calculations; possibly the teaching here was effective in overcoming initial problems with arithmetic, allowing success of students in the final test. Thirdly, the review test focused on computational ability only, while the medication dose calculation test included arithmetic calculations plus a conceptual framework of medication orders to make the final calculations. Perhaps this contextualization of the problems provided an enhanced understanding of how the arithmetic functions connect to perform this specialized math.

The role of math anxiety in affecting the ability of nursing students to accurately calculate medication doses underlines the importance of understanding the factors that predict math anxiety in nursing students. The Inchworm personality was found to be predictive of math anxiety (see Table 3 ). The majority of the nursing students in this study fell into the Inchworm group (61\%), while the Grasshopper personality was least common (16\%); the remaining $23 \%$ of participants exhibited an Intermediate personality. The distribution of students across personality types differs from the previous study which found the Intermediate personality to be the dominant math personality as opposed to the Inchworm predominance 
found here, but both studies found the Grasshopper personality to be least common math personality in nursing students. ${ }^{[15]}$ Understanding the math personalities of the majority of students in a class may be helpful in nursing education to tailor approaches for the majority of students. Inchworm math personality involves the step-by-step approach to problem solving which lends itself to teaching interventions more readily than the intuitive Grasshopper approach. With respect to math personality, it may be quite helpful to consider the $4 \mathrm{C}$ model of teaching dose calculations - compute, convert, conceptualize, and critically evaluate ${ }^{[33]}$ Inchworm students have significantly more trouble conceptualizing a problem. Inchworm students rely on the use of a formula that can be consistently applied to solve a problem. Inchworm students may be less able to provide critical evaluation of their answer as they simply accept the result determined from the formula or calculator. The inclusion of Simulation as a teaching strategy for medication dose calculations may be helpful with these Inchworm problems. Simulation has been shown to increase student learning of dose calculations, ${ }^{[2,47-49]}$ because it provides context and understanding of the situation. Providing this context may also be helpful to Grasshopper students who are unfamiliar with the clinical setting. ${ }^{[9,28,50]}$

The approach to preparation for the medication dose calculation test was also found to be predictive of math anxiety in first year baccalaureate students (see Table 3). As far as we are aware, no previous studies have performed to examine this variable with performance of medication dose calculations. In this study, individuals who used 0-2 strategies to prepare for the medication dose calculation test were differentiated from individuals who used 3-4 interventions. This is because investigators postulated that all students would use the textbook and class notes at minimum to study for the test, whether they understood to check those or not as an strategy for preparation. Students who used more than these two strategies would therefore be exceeding expectations to prepare for the medication dose calculation test. Logically, it follows that individuals who are more anxious about the test would use a greater number of strategies to ensure that they were well prepared and to increase their chances for success on the test. The presence of anxiety was found to be high in students who participated in voluntary remedial math tutorials. ${ }^{[45]}$ The use of a variety of different strategies to prepare for the medication dose calculation tests also fits with the methodical Inchworm math personality. Success on the test, however, was not related to the number of strategies used in preparation for the test (see Table 2). This emphasizes the fact that anxiety, not preparation, is the important variable influencing performance. Educators need to understand which extra resources that students are using in their test preparation, and learn which methods are effective to allow direction of students to those appropriate resources.

Findings from this study clearly indicate that math anxiety is a key predictor of performance of first year baccalaureate nursing students on a medication dose calculation test. Several specific teaching and learning strategies that could be potentially useful to reduce math anxiety can be extrapolated from the results of this study. The development of a dedicated Math for Nursing course can provide more in-depth opportunities for learning and reduce math anxiety; when asked, nurses would have preferred to have a dedicated course like this during their education. ${ }^{[36]}$ This course should include the consistent use of one formula for students. ${ }^{[16,33,51]}$ The development of an in-course math buddy program, which would include compressed students as peer mentors for collaborative students, could help to reduce math anxiety and improve the ability of students to succeed on a medication dose calculation test. Supplemental math tutorials run by instructors ${ }^{[45]}$ or voluntary workshops run by peer mentors ${ }^{[52]}$ improved scores on medication dose calculation tests. Anxiety was decreased by the instructor-led tutorials. ${ }^{[45]}$ Inchworm students particularly may benefit from remedial tutorials that incorporate stepwise logical reasoning combined with reflection; this approach increases confidence. ${ }^{[53]}$ An inverse relationship exists between confidence/self-efficacy and math anxiety, so strategies that improve confidence should reduce anxiety. ${ }^{[13,16]}$ A dedicated course should include simulation; when a clinical simulation is used, students get a chance to see the dosage calculation question in the context of a whole clinical situation. ${ }^{[54]}$ Simulation provides the opportunity to enhance exposure to clinical situations which enhances learning ${ }^{[9,15,28,50,55]}$ as well as the practical approach of instant feedback from the instructor. Math, including medication dose calculation, is a social and contextual experience; experienced nurses, when asked how they calculate doses, were more accurate when doing calculations that they perform every day as they could envision the process as they worked through the math. ${ }^{[29]}$ Simulations can range from simple experiences, for example questions presented with visual aids like a bottle of pills or a syringe, to complex experiences such as staged clinical situations where actors are employed to act as the patient and the student has to interpret medication orders and complete a dosage calculation before administering the medication. Both low fidelity simulations ${ }^{[47,48,56]}$ and high fidelity simulations ${ }^{[32]}$ improve dose calculation test scores. The use of standardized patients in dose calculation simulations improves test scores and reduces math anxiety. ${ }^{[49]}$ Threading the learning of calculations throughout the curriculum matched to the clinical setting of the students may support this contextual learning. 
Teaching medication dose calculations has traditionally involved faculty demonstrating the formulas and the providing practice questions both in the classroom and for further work at home. The "absolutist"[57] approach works successfully for some nursing students, possible the Grasshopper personality, but not all. A stand-alone medication dose calculation course developed based on the constructivist philosophy will provide the "multiple perspectives, authentic activities, realworld environments" ${ }^{\text {[58] }}$ that may successfully connect to each individual learner and enhance learning. Increased success in tests for dose calculations has been demonstrated using a constructivist-based approach to design high fidelity simulation activities, ${ }^{[59]}$ an online module ${ }^{[60]}$ or traditional classroom activities. ${ }^{[58]}$ A simulated clinical experience around medication dose calculations significantly decreased medications errors in nursing students during a subsequent clinical rotation. ${ }^{[61]}$ The active learning strategies used in the constructivist approach may help promote conceptual understanding and students to engage at their own individual level to work through confusion ${ }^{[62]}$ and master medication dose calculations. Whether the delivery of these learning activities should be online or in a traditional classroom setting is unclear. All teaching strategies improve dose calculation test results over pre-test levels; ${ }^{[11,16]}$ this includes online learning ${ }^{[45,63,64]}$ or classroom teaching. ${ }^{[63,65]}$ The use of a dose calculation mobile app both improved test scores and reduced anxiety. ${ }^{[66]}$

Reducing math anxiety using the strategies outlined above will enhance the ability of Inchworm students to compute and convert numbers to perform medication dose calculations accurately. Nursing educators must provide a variety of learning and review resources to support arithmetic ability; the presence of these resources is more important that the type of resource ${ }^{[16,51]}$ Understanding the role for calculators in teaching and testing is important as this increase confidence in students. ${ }^{[10]}$
The use of the review test as an approximation of baseline arithmetic ability is a limitation of this study because there is no assurance that students completed the tests alone without the use of a calculator. Another limitation in this study comes from not accounting for gender differences in math performance and anxiety due to time constraints, as this work was part of a fourth year thesis. Male students tend to show less math anxiety and perform better than females on mathrelated tasks; ${ }^{[67]}$ a future analysis of gender would be useful because this information could be used to design more specific teaching strategies to reduce anxiety in female students. Another limitation is that this work is from a single site and only involves first year $\mathrm{BScN}$ students. A final limitation in the study design is its implicit reliance on self-reports using online surveys from participants to collect data.

\section{Conclusion}

Math anxiety is a key predictor of performance by first year baccalaureate nursing students on a medication dose calculation test. Compressed students, who have had previous university experience, have lower math anxiety levels and a higher mastery of medication dose calculations than younger, collaborative students. Students who experience greater math anxiety use a greater variety of strategies to prepare for the medication dose calculations test and are also students who have an Inchworm math personality. Therefore effective strategies that will alleviate math anxiety must be considered when designing strategies for teaching medication dose calculations to nursing students. These strategies must include a consideration of successful approaches to teaching students who possess the step-by-step Inchworm math personality.

\section{ACKNOWLEDGEMENTS}

We are grateful to Dr. S Chinn for sharing his math personality assessment.

\section{CONFLICTS OF INTEREST Disclosure}

The authors declare that there is no conflict of interest.

\section{REFERENCES}

[1] Armitage GR, Knapman HF. Adverse events in drug administration: a literature review. Journal of Nursing Management. 2003; 11: 130-140. https://doi.org/10.1046/j.1365-2834.2003.00359.x

[2] Leufer T, Cleary-Holdforth J. Let's do no harm: Medication errors in nursing: Part 1. Nurse Education in Practice. 2013; 13(3): 213-216. PMid:23474430 https://doi.org/10.1016/j.nepr.2013.01 .013

[3] Cleary-Holdforth J, Leufer T. The strategic role of education in the prevention of medication errors in nursing: Part 2. Nurse Education in Practice. 2013; 13(3): 217-220. PMid:23481625 https: //doi.org/10.1016/j.nepr.2013.01.012

[4] Bagnasco A, Galaverna L, Aleo G, et al. Mathematical calculation skills required for drug administration in undergraduate nursing students to ensure patient safety: A descriptive study. Drug calculation skills in nursing students. Nurse Education in Practice. 2016; 16(1): 33-39. https://doi.org/10.1016/j.nepr.2015.06.006

[5] Jukes L, Gilchrist M. Concerns about numeracy skills of nursing students. Nurse Education in Practice. 2006; 6(2006): 192-198. https://doi.org/10.1016/j.nepr.2005.12.002

[6] Grandell-Niemi H, Hupli M, Leino-Kilpi H, et al. Medication calculation skills of nurses in Finland. Journal of Clinical Nursing. 2003; 
12: 519-528. https://doi.org/10.1046/j.1365-2702.2003 $.00742 . x$

[7] McMullan M, Jones R, Lea S. Patient safety: Numerical skills and drug calculation abilities of nursing students and Registered Nurses. Journal of Advanced Nursing. 2010; 66(4): 891-899. PMid:20423376 https://doi.org/10.1111/j.1365-2648.2010.05258.x

[8] Ramjan LM. Contextualism adds realism: nursing students' perceptions of and performance in numeracy skills tests. Nurse Education Today. 2011; 31(8): e16-e21. https://doi.org/10.1016/j.ne dt.2010.11.006

[9] Barkhouse-MacKeen CD, Murphy AL. Pharmacology in undergraduate nursing education: Innovative strategies for enhancing medication related knowledge, attitudes, skills and behaviours. Journal of Nursing Education and Practice. 2013; 3(6): 91-101. https: //doi.org/10.5430/jnep.v3n6p91

[10] Bull H. Identifying maths anxiety in student nurses and focusing remedial work. Journal of Further and Higher Education. 2009; 33(1): 73-81. https://doi.org/10.1080/03098770802638689

[11] Hunter-Revell SM, McCurry MK. Effective pedagogies for teaching math to nursing students: a literature review. Nurse Educ. Today. 2013; 33(11): 1352-1356. https://doi.org/10.1016/j.nedt .2012 .07 .014

[12] Mackie JE, Bruce CD. Increasing nursing students' understanding and accuracy with medical dose calculations: A collaborative approach. Nurse Education Today. 2016; 40: 146-153. PMid:27125165 https://doi.org/10.1016/j.nedt.2016.02.018

[13] McMullan M, Jones R, Lea S. Math anxiety, self-efficacy, and ability in British undergraduate nursing students. Research in Nursing and Health. 2012; 35: 178-186. PMid:22261975 https ://doi .org/10 $.1002 /$ nur .21460

[14] Ramjan LM, Stewart L, Salamonson Y, et al. Identifying strategies to assist final semester nursing students to develop numeracy skills: a mixed methods study. Nurse Education Today. 2014; 34(2014): 405412. PMid:23623279 https://doi.org/10.1016/j.nedt. 201 3.03.017

[15] Weeks KW, Clochesy JM, Hutton BM, et al. Safety in numbers 4: The relationship between exposure to authentic and didactic environments and nursing students' learning of medication dosage calculation problem solving knowledge and skills. Nurse Education in Practice. 2013; 13(2): e43-e54. https://doi.org/10.1016/j.nepr.2012.10 .010

[16] Williams B, Davis S. Maths anxiety and medication dosage calculation errors: A scoping review. Nurse Education in Practice. 2016; 20: 139-146. PMid:27589091 https://doi.org/10.1016/j.ne pr.2016.08.005

[17] Fulton \& O'Neill. Mathematics anxiety and its effect on drug dose calculation. Journal of Nursing Education. 1989; 28(8): 343-346.

[18] Feizalahzadeh H, Valizadeh S, Avari M, et al. A Study on the Effect of Lecture and Multimedia Software on Drug Calculation and Prescription: A Systemic Review. Crescent Journal of Medical and Biological Sciences. 2016; 3(3): 75-80.

[19] Keers R, Williams S, Cooke J, et al. Prevalence and nature of medication administration errors in health care settings: A systematic review of direct observational evidence. Annals of Pharmacotherapy. 2013; 47: 237-56. PMid:23386063 https://doi .org/10.1345/ aph.1R147

[20] LaPointe NM, Jollis JG. Medication errors in hospitalized cardiovascular patients. ACC Curr. J. Rev. 2003; 12(5): 21. https: //doi.org/10.1016/j. accreview. 2003.08.065

[21] Ozyazicioglu N, Aydin AI, Surenler S, et al. Evaluation of students' knowledge about pediatric dosage calculations. Nurse Education in
Practice. 2018; 28: 34-39. PMid:28942096 https ://doi.org/10 $.1016 / j$.nepr. 2017.09.013

[22] Eley R, Sinnott M, Steinle V, et al. The need to address poor numeracy skills in the emergency department environment. EMA - Emergency Medicine Australasia. 2014; 26(3). https://doi.org/10.1111/ 1742-6723. 12207

[23] Grillo JA, Latif DA, Stolte SK. The relationship between preadmission indicators and basic mathematics skills at a new school of pharmacy. Annals of Pharmacotherapy. 2001; 35: 167-172. PMid:11215834 https://doi.org/10.1345/aph.10205

[24] Parshuram CS, To T, Seto W, et al. Systematic evaluation of errors occurring during the preparation of intravenous medication. Can Med. Assoc. J. 2008; 178(1): 42-48. https://doi.org/10.1503/ cmaj. 061743

[25] Dilles T, VanderStichele R, VanBortel L, et al. Nursing students' pharmacological knowledge and calculation skills. Ready for practice? Nurse Education Today. 2011; 31(5): 499-505. https: //doi.org/10.1016/j.nedt.2010.08.009

[26] Eastwood KJ, Boyle MJ, Williams B, et al. Numeracy skills of nursing students. Nurse Education Today. 2011; 31: 815-818. PMid:21239088 https://doi.org/10.1016/j.nedt.2010.12.014

[27] Costello M. Predictors of success on medication calculation tests Nurse Educator. 2011a; 36(1): 11-12. https://doi .org/10.109 7/NNE. 0b013e3182001c25

[28] Wright $\mathrm{K}$. The assessment and development of drug calculation skills in nurse education - A critical debate. Nurse Education Today. 2009; 29: 544-548. PMid:19324475 https://doi.org/10.1016/j.ne dt. 2008.08.019

[29] Wright K. How do nurses solve drug calculation problems? Nurse Education Today. 2013; 33: 450-457. https://doi.org/10.101 $6 / j$.nedt. 2012.04.009

[30] Bath JB, Blais K. Learning style as a predictor of drug calculation ability. Nurse Educator. 1993; 18(1): 33-36. https : //doi .org/10 .1097/00006223-199301000-00011

[31] Hegge M, Larson V. Stressors and coping strategies of students in accelerated baccalaureate nursing programs. Nurse Educator. 2008; 33(1): 26-30. PMid:18091468 https://doi.org/10.1097/01.N NE. 0000299492.92624 .95

[32] Hurley TV. Experiential Teaching Increases Medication Calculation Accuracy Among Baccalaureate Nursing Students. Nursing Education Perspectives. 2017; 38(1): 34-36. PMid:29194242 https: //doi.org/10.1097/01.NEP.0000000000000097

[33] Johnson S, Johnson L. The 4 Cs: a model for teaching dosage calculation. Nurse Educator. 2002; 27(2): 79-83. https : //doi .org/10 .1097/00006223-200203000-00011

[34] Rainboth L, DeMasi C. Nursing students' mathematics calculation skills. Nurse Education Today. 2006; 26(8): 655-661. PMid:17034904 https://doi.org/10.1016/j.nedt.2006.07 .022

[35] Kapborg I, Rosander R. Swedish student nurses solving mathematical items with or without help of a hand-held calculator - a comparison of results. Nurse Education in Practice. 2001; 1: 80-84. PMid:19036248 https://doi.org/10.1054/nepr.2001.0012

[36] Jarvis DH, Kozuskanich A, Law B, et al. The techno-numerate nurse: results of a study exploring nursing student and nurse perceptions of workplace mathematics and technology demands. Quality Advancement in Nursing Education. 2015; 1(2). https://doi.org/10.1 7483/2368-6669.1024

[37] Glaister K. The presence of mathematics and computer anxiety in nursing students and their effects on medication dosage calculations. Nurse Education Today. 2007; 27(4): 341-347. PMid:16857301 https://doi.org/10.1016/j.nedt.2006.05.015 
[38] Andrew S, Salamonson Y, Halcomb EJ. Nursing students' confidence in medication calculations predicts math exam performance. Nurse Education Today. 2009; 29(2): 217-223. https ://doi .org/10.1 016/j.nedt. 2008.08 .005

[39] Røykenes K, Smith K, Larsen TMB. "It is the situation that makes it difficult": Experiences of nursing students faced with a high-stakes drug calculation test. Nurse Education in Practice. 2014; 14: 350-356. PMid:24462630 https ://doi.org/10.1016/j.nepr.2014.01 .004

[40] Bath JB, Chinn SJ, Knox DE. Test of cognitive style in mathematics emanual. Slosson Educational Publications, East Aurora, New York. 1986.

[41] Alexander L, Martray C. The development of an abbreviated version of the Mathematics Anxiety Rating Scale. Measurement and Evaluation in Counselling and Development. 1989; 22(3): 143-150. https://doi.org/10.1080/07481756.1989.12022923

[42] Chinn S. Beliefs, Anxiety, and Avoiding Failure in Mathematics. Child Development Research. 2012. https ://doi .org/10.1155/ 2012/396071

[43] Green S. How many subjects does it take to do a regression analysis? Multivariate Behav Res. 1991; 26(3): 499-510. PMid:26776715 https ://doi.org/10.1207/s15327906mbr2603_7

[44] Sherriff K, Burston S, Wallis M. Effectiveness of a computer based medication calculation education and testing programme for nurses. Nurse Education Today. 2012; 32: 46-51. PMid:21345550 https : //doi.org/10.1016/j.nedt.2011.01.020

[45] Choudhary R, Malthus C. The impact of targeted mathematics/numeracy tutorials on maths anxiety, numeracy and basic drug calculation exam marks. Journal of Academic Language and Learning. 2017; 11(1): A1-A22.

[46] Reason J. Human error: models and management. BMJ. 2000; 320: 768-770. https://doi.org/10.1136/bmj .320.7237.768

[47] Baginski M. Use of Low-Fidelity Simulation Within a Medication Calculation Nursing Course to Enhance Students' Understanding of Accuracy. Nurse Educator. 2017; 42(3): 110-111. PMid:27723685 https://doi.org/10.1097/NNE.0000000000000334

[48] Basak T, Aslan O, Unver V, et al. Effectiveness of the training material in drug-dose calculation skills. Japan Journal of Nursing Sciences. 2016; 13(3): 324-330. PMid:26782270 https://doi.org/10.1 $111 /$ jjns. 12112

[49] Ham L. Use of Standardized Patients to Enhance Simulation of Medication Administration. Nurse Educator. 2016; 41(4): 166-168. PMid:26862688 https ://doi.org/10.1097/NNE.0000000000 000248

[50] Costello M. The use of simulation in medication calculation instruction: a pilot study. Nurse Educator. 2011b; 36(5): 181-182. https://doi.org/10.1097/NNE.0b013e3182297a1d

[51] Härkänen M, Voutilainena A, Turunen E, et al. Systematic review and meta-analysis of educational interventions designed to improve medication administration skills and safety of registered nurse. Nurse Education Today. 2016; 41: 36-43. PMid:27138480 https://doi.org/10.1016/j.nedt.2016.03.017

[52] Greenleaf Brown L, Curtis A, Harris LC. Improving Dose Calculation Pass Rates With Peer Tutoring. Journal of Nursing Education. 2019; 58(3): 188. PMid:30835812 https://doi.org/10.3928/ 01484834-20190221-15

[53] Shelton C. Students who developed logical reasoning skills reported improved confidence in drug dose calculation: Feedback from reme- dial maths classes. Nurse Education Today. 2016; 41(2016): 6-11. PMid:27138475 https://doi.org/10.1016/j.nedt.2016.03 .007

[54] Zahara-Such RM. Improving medication calculations of nursing students through simulation: An integrative review. Clinical Simulation in Nursing. 2013; 9(9): e379-e383. https ://doi.org/10.1016/ j.ecns. 2012.08.003

[55] Benner P, Sutphen M, Leonard V, Day L. Educating nurses: A call for radical transformation. San Francisco, CA: Jossey-Bass; 2010.

[56] Dubovi I, Levy S, Dagan E. Situated Simulation-Based Learning Environment to Improve Proportional Reasoning in Nursing Students. International Journal of Science and Mathematics Education. 2018; 16(8): 1521-1539. https://doi.org/10.1007/s10763-017-9 842-2

[57] Ocean J, McGrath I. Pre-Service teachers Developing Numeracy Skills in Nurses: A Constructivist Approach. ICERI2016 Proceedings. 2016; 1: 4214-4130.

[58] Murphy E. Constructivism: From philosophy to practice. 1997. Available from: http://www.ucs.mun.ca/ emurphy/stemnet/cle .html

[59] Newton SE, Harris M, Pittiglio L. Constructivist Philosophy and Nursing Student Medication Calculations. Research and Theory for Nursing Practice: An International Journal. 2013; 27(2): 88-94. https://doi.org/10.1891/1541-6577.27.2.88

[60] Mosca C. Using Constructivist Learning Theory to Create and Implement a Pilot Online Dosage Calculation Module. Journal of the New York State Nurses Association. 2017; 45(1): 44-49.

[61] Sears K, Goldsworthy S, Goodman WM. The relationship between simulation in nursing education and medication safety. Journal of Nursing Education. 2010; 49(1): 52-55. PMid:19810664 https : //doi.org/10.3928/01484834-20090918-12

[62] Mills S. Teaching and Learning Medication Calculations: A Grounded Theory of Conceptual Understanding. International Journal of Nursing Education Scholarship. 2016; 13(1): 1-9. https : //doi.org/10.1515/ijnes-2015-0076

[63] Simonsen BO, Daehlin GK, Johansson I, et al. Improvement of drug dose calculations by classroom teaching or e-learning: A randomised controlled trial in nurses. BMJ Open. 2014; 4: e006025. https://doi.org/10.1136/bmjopen-2014-006025

[64] Aydin AK, Dinc L. Effects of Web-Based Instruction in Nursing Students' Arithmetical and Drug Dosage Calculation Skills. CINCOMPUTERS INFORMATICS NURSING. 2017; 35(5): 262-269. PMid:28045702 https://doi.org/10.1097/CIN.0000000000 000317

[65] VanLacker A, Baldewijns K, Verhaeghe R, et al. The effectiveness of an e-learning course on medication calculation in nursing students: a clustered quasi-experimental study. Journal of Advanced Nursing. 2016; 72(9): 2054-2064. PMid:27060466 https : //doi.org/10.1111/jan.12967

[66] McMullen M. Evaluation of a medication calculation mobile app using a cognitive load instructional design. International Journal of Medical Informatics. 2018; 118: 72-77. PMid:30153925 https: //doi.org/10.1016/j.ijmedinf .2018.07.005

[67] Devine A, Fawcett K, Szuca D, et al. Gender differences in mathematics anxiety and the relation to mathematics performance while controlling for test anxiety. Behavioural and Brain Functions. 2012; 8(33): 2-9. https ://doi.org/10.1186/1744-9081-8-33 